\title{
Constipation is the Most Frequent Cause of Chronic Abdominal Pain in Children
}

\author{
Vera Loening-Baucke ${ }^{*}, 1$ and Alexander Swidsinski ${ }^{2}$ \\ ${ }^{I}$ Division of General Pediatrics, University of Iowa, USA \\ ${ }^{2}$ Charité Hospital at the Humboldt University in Berlin, Germany
}

\begin{abstract}
The aims of the study were to identify the frequency and causes of chronic abdominal pain in a large academic primary care population at the University of Iowa Children's Hospital. We evaluated retrospectively the complete charts of children $\geq 4$ years old, seen for at least one health maintenance visit in the primary paediatric clinic during a 6-month period, for complaints and causes of chronic abdominal pain. Of 493 boys and 469 girls with a mean age of 9.1 years, $12.7 \%$ had been evaluated for chronic abdominal pain. Constipation as cause of abdominal pain occurred in $83 \%$, childhood functional abdominal pain in $8 \%$, colic in $5 \%$, gastroesophageal reflux in $2 \%$ and infection in $2 \%$. The life-time prevalence rate for chronic abdominal pain was $13.3 \%$; was due to functional causes in $13.1 \%$ and due to organic diseases in $0.2 \%$. Functional constipation was the most frequent cause of chronic abdominal pain in a large primary care paediatric population.
\end{abstract}

Keywords: Retrospective study, functional abdominal pain, functional constipation, children.

\section{INTRODUCTION}

Abdominal pain is among the most common complaints of childhood worldwide. It affects the child's wellbeing, and the cost from missed school days and use of healthcare resources are high [1]. In clinical practice, it is generally believed that intermittent or constant abdominal pain that exceeds 2 or 3 months in duration can be considered chronic [2-4]. Chronic abdominal pain occurs in more than $10 \%$ of children [5]. The role of gender remains undefined. Chronic abdominal pain can be due to functional as well as organic causes. Functional abdominal pain is abdominal pain without evidence of an inflammatory, anatomic, metabolic or neoplastic disorder $[6,7]$. It is thought that children with functional gastrointestinal disorders such as recurrent or chronic abdominal pain have abnormal bowel reactivity to physiologic stimuli, such as a meal, gut distension and hormonal changes; to noxious stimuli such as inflammatory processes; or psychological stressful stimuli, such as anxiety and separation anxiety. Only in a small number of children is the chronic abdominal pain caused by an underlying organic disease.

We had noticed that many of the children, attending our primary care clinic with a complaint of chronic abdominal pain, had underlying constipation. Because of the significant direct and indirect costs associated with chronic abdominal pain in children, our aims were to evaluate the causes of chronic abdominal pain, determine the frequency of underlying constipation and to evaluate the life-time prevalence rate of chronic abdominal pain in a large academic primary care population.

*Address correspondence to this author at the Children's Hospital of the University of Iowa, 200 Hawkins Drive, Iowa City, IA 52242, USA; Tel: 319-356-1832; Fax: 319-356-4855;

E-mail: vera-loening-baucke@uiowa.edu

\section{MATERIAL AND METHODS}

\section{Identification of the Study Population}

We evaluated the medical records of all children, 4 to 17 years of age, who attended the primary pediatric clinics at the University of Iowa Children's Hospital for at least one health maintenance visit, during a 6-month period from January 2 to June 30, 2004. To identify these children, a computer search was performed using the codes for initial and return well child visits (99382, 99392, 99383, 99393, 99384, and 99394 from the Current Procedure Terminology) [8] and $\geq 4$ years of age.

\section{Identification of Children with Abdominal Pain through Manual Chart Review}

The medical records of all identified children, from birth to the present age, were retrospectively reviewed. In the United States, many parents use the emergency department as a convenient way of having a child examined for abdominal pain after working hours and on weekends, when the acute clinics are closed. Therefore any visit for chronic abdominal pain with or without other gastrointestinal symptoms to the primary care clinics or emergency department were included. Medical visits for primarily chronic abdominal pain with or without other gastrointestinal symptoms were reviewed in detail for complaints of abdominal pain, duration of this complaint, symptoms of constipation, other symptoms, and final diagnosis for the abdominal pain. These data were entered into a pre-designed data collection form which was developed for this study. The authors assigned a final diagnosis for each patient, depending on symptoms, physical findings, blood tests, cultures, X-rays, when available, and/or response to treatment and resolution of the abdominal pain with treatment.

\section{Setting}

The subjects were children of employees and students of the University of Iowa and children from the community 
who received their primary care in our clinics. Most of the children were Caucasian, few were African-American and children of international students. Iowa City has a population of 80,000 citizens and 30,000 students. The surrounding is rural.

The primary care was provided by 10 staff pediatricians, increasing later to 17 , with the author being one of them. Referred patients were not evaluated in our primary care clinics and were not included.

The study was approved by the Institutional Human Research Review Committee.

\section{Definitions}

Apley and Naish [3] defined recurrent abdominal pain as at least 3 episodes of pain occurring within 3 months that are severe enough to affect the child's activities. We used the following definition for functional abdominal pain [4]: the child had to have periodic or constant abdominal pain with functional impairment for at least 2 months and an unremarkable physical examination and diagnostic evaluation, except related to stool retention. The term chronic abdominal pain includes all causes, functional as well as organic causes.

Functional constipation was defined by the classical Iowa criteria, which we and others have used for more than 20 years [9-13]. Functional constipation was defined by a duration of at least 2 months. The criteria for functional constipation in children $\geq 4$ years of age are given in Table 1 . The same criteria for constipation were also used for children $<4$ years of age, except fecal incontinence was not included.

\section{Table 1. Criteria for Functional Constipation}

Functional constipation was defined by a duration of at least 2 months and by $\geq 2$ of the following characteristics in children $\geq 4$ years of age:

1. Frequency of bowel movements of less than three stools per week

2. $\geq 1$ episode of faecal incontinence (formerly called encopresis) per week

3. History of retentive posturing (or excessive volitional stool retention)

4. History of painful or hard bowel movements

5. Large stools in the rectum or felt on abdominal examination, or

6. Passing of stools so large that they obstruct the toilet

Colic is a symptom complex of early infancy that is characterized by paroxysms of irritability, fussing, or crying, that starts and stops without obvious cause, episodes lasting for $\geq 3$ hours per day and occurring at least three times per week for at least one week [14].

\section{Data Analyses}

The relevant information was abstracted and entered into a pre-designed data collection form. Patient characteristics were summarized using observed proportions, means, standard deviations and ranges. T-test, $\mathrm{X}^{2}$-test and Fisher's exact test were used. Significance was accepted at $p<0.05$. Results were expressed as mean \pm standard deviation or percent. For defining life-time prevalence rate, we restricted the patient population to those who were served by our clinics since birth or starting in the first 2 months of life. This prevalence was calculated by dividing the number of children with chronic abdominal pain in this group by the total number in this group multiplied with 100 .

\section{RESULTS}

The computer identified 1002 children, 4 to 17.9 years of age. Their complete medical records were retrospectively reviewed. Forty children were excluded because of chronic diseases, such as cerebral palsy with severe mental retardation, severe mental retardation due to chromosomal abnormalities, severe cardiac abnormalities with surgical procedures such as cardiac transplant or pacemaker implant, and one child with ulcerative colitis, diagnosed in infancy. Therefore the study included 962 children (493 boys, 469 girls) with a mean age of $9.1 \pm 3.9$ years, median 8.6 years. Their medical records were reviewed in depth.

Chronic abdominal pain (of $\geq 2$ months duration) was evaluated in $122(12.7 \%)$ children, 53 boys and 69 girls $(10.8 \%$ versus $14.7 \% ; p=0.062)$. The first visit for chronic abdominal pain occurred at a mean age of $6.6 \pm 3.9$ years, median 6.3 years, range 2 months to 17.5 years. One hundred and fourteen of these 122 children (93\%) were first evaluated in the primary care clinic and 8 were evaluated in the emergency room.

\section{Causes of Chronic Abdominal Pain}

One hundred and twenty-two children had been examined for chronic abdominal pain. Chronic abdominal pain occurred in 53 boys (10.8\%) (Table 2). The pain in boys was due to functional constipation 44 times, due to childhood functional abdominal pain 5 times, and due one time each to colic and gastroesophageal reflux disease, Cryptosporidium infection and Entamoeba histolytica infection.

Table 2 shows the data for the 69 girls (14.7\%) with chronic abdominal pain. The pain in girls was due to functional constipation 57 times, due to colic 5 times, childhood functional abdominal pain 5 times, and one time each to gastroesophageal reflux disease and to side pain during running.

There was no significant difference in causes of abdominal pain in boys and girls.

Only 5 children had a second episode of chronic abdominal pain with a different symptom combination later in life and received for the second episode a different diagnosis. Two children with functional constipation were later evaluated for aerophagia, one child with colic as an infant was evaluated at 5 years of age for functional constipation with faecal incontinence, and two children suffered later from gastroesophageal reflux disease.

Overall only $5.7 \%$ of the chronic abdominal pain in boys and $1.4 \%$ in girls were due to organic disease. Abdominal pain was due to functional causes in $95.9 \%$.

The frequency of symptoms which supported a diagnosis of functional constipation is listed in Table $\mathbf{3}$. The presence or absence of all symptoms or physical findings was not recorded for each child, but all constipated children fit the criteria for functional constipation. Ninety-four children of the 101 children $(93 \%)$, who had functional constipation as the cause of their abdominal pain, were first evaluated in the primary care clinic and 7 were seen in the emergency room. All constipated children had 2 to $>30$ follow-up visits in our primary care clinics (mean $17 \pm 9$ ) after the first visit for 
Table 2. Chronic Abdominal Pain and Causes

\begin{tabular}{|c|c|c|c|}
\hline \multirow{2}{*}{ Number (\%) } & \multicolumn{3}{|c|}{ Chronic Abdominal Pain } \\
\hline & All children 122 (12.7\%) & Boys $53(10.8 \%)$ & Girls $69(14.7 \%)$ \\
\hline $\begin{array}{l}\text { 1. Due to functional GI disorders: } \\
\text { Due to functional constipation } \\
\text { Not related to functional constipation } \\
\text { Childhood functional abdominal pain } \\
\text { Colic }\end{array}$ & $\begin{array}{c}117(95.9 \%) \\
101(82.8 \%) \\
16(13.1 \%) \\
10(8.2 \%) \\
6(4.9 \%)\end{array}$ & $\begin{array}{c}50(94.3 \%) \\
44(83 \%) \\
6(11.3 \%) \\
5 \\
1\end{array}$ & $\begin{array}{l}67(97.1 \%) \\
57(82.6 \%) \\
10(14.5 \%) \\
\quad 5 \\
5\end{array}$ \\
\hline $\begin{array}{l}\text { 2. Due to organic causes: } \\
\text { Gastroesophageal reflux } \\
\text { Chronic infection* }\end{array}$ & $\begin{array}{c}4(3.3 \%) \\
2 \\
2\end{array}$ & $\begin{array}{c}3(5.7 \%) \\
1 \\
2\end{array}$ & $\begin{array}{c}1(1.4 \%) \\
1 \\
0\end{array}$ \\
\hline 3. Side pain during running & $1(0.8 \%)$ & 0 & $1(1.4 \%)$ \\
\hline
\end{tabular}

*Cryptosporidium infection and Entamoeba histolytica infection in one child each.

abdominal pain. Only 3 children had $<4$ follow-up visits, with one having 2 follow-up visits only. Our outcome data documented relief of abdominal pain with adequate laxative treatment in these 101 children.

We did not find a risk that the selected population in our study was biased towards the sick, in larger need of a checkup. Twelve of the 962 children (1\%) came to the primary care clinic with a new complaint of abdominal pain during the six-month period of patient selection.

\section{Life-Time Prevalence Rates of Chronic Abdominal Pain}

To evaluate the life-time prevalence rate of chronic abdominal pain, we evaluated all 435 children (226 boys and 209 girls) with a mean age of $8.5 \pm 3.8$ years, median 7.4 years, who were born in our hospital $(n=410)$ or joined our primary care clinic within the first 2 months of life $(n=25)$. Fifty-eight children (13.3\%) had been evaluated for chronic abdominal pain, 28 boys and 30 girls. The abdominal pain was due to functional constipation 49 times $(84.5 \%)$, to colic 6 times $(10.3 \%)$, to childhood functional abdominal pain twice $(3.4 \%)$, and to gastroesophageal reflux disease once $(1.7 \%)$. Therefore, only one child had an organic disease as the cause of the abdominal pain $(0.2 \%)$, while $57(13.1 \%)$ of these 435 children had functional abdominal pain. Table 4 shows the age at the time of the first clinic visit for func- tional abdominal pain and the age distribution of the children at the time of inclusion into the study. The onset of functional abdominal pain occurred significantly more frequently before 8 years of age than after 8 years of age $(p<0.001)$.

\section{DISCUSSION}

We retrospectively generated data from a primary care setting to determine the causes of chronic abdominal pain in children. We found that $12.7 \%$ of the children had experienced chronic abdominal pain. There was no significant difference in the frequency and causes of abdominal pain in boys and girls. Prevalence rates for recurrent abdominal pain have been reported in a large British population cohort study: $3.8 \%$ of 2 -year-olds, $6.9 \%$ of 3 -year-olds and $11.8 \%$ of 6-year-old children had functional abdominal pain [15]. In another cohort study from Southeast Sweden, Ludvigsson et al. [16] using parental questionnaires to evaluate 8341 children at birth, one year and 2.5 years of age, found that $5.7 \%$ suffered from abdominal pain and $6.5 \%$ from constipation. In a community-based study in the United States, some abdominal pain was reported in $75 \%$ of adolescents [17]. In this study, $13 \%$ of middle school and $17 \%$ of high school students reported at least weekly abdominal pain, $21 \%$ reported abdominal pain severe enough to affect daily activity. The prevalence rates ranged from $0.3 \%$ to $19 \%$ in a systemic review of the published literature on childhood recurrent

Table 3. Symptoms of Functional Constipation in 101 Children with Abdominal Pain

\begin{tabular}{|l|c|c|c|}
\hline & Symptom Reported as Present/Absent n* & Symptom Documented n & Symptom Present in \\
\hline \hline$<3$ bowel movements/week & $35 / 54$ & 89 & $35 \%$ \\
\hline $\begin{array}{l}\text { Retentive posturing/ } \\
\text { excessive volitional stool retention }\end{array}$ & $23 / 26$ & 49 & $23 \%$ \\
\hline$\geq 1$ times fecal incontinence/week & $18 / 77$ & 96 & $18 \%$ \\
\hline Painful or hard stools & $81 / 14$ & 95 & $80 \%$ \\
\hline Large stool in the rectum & $77 / 18$ & 95 & $76 \%$ \\
\hline Large stool in abdomen & $53 / 48$ & 101 & $51 \%$ \\
\hline Stools obstruct the toilet & $29 / 55$ & 84 & $28 \%$ \\
\hline Blood in stool & $13 / 84$ & 97 & $13 \%$ \\
\hline
\end{tabular}

The number of children evaluated for each finding. Not all symptoms or physical findings were documented for each child. 
Table 4. Data for the 435 Children who Joined Our Clinic from Birth or within 2 Months of Life

\begin{tabular}{|l|c|c|c|c|}
\hline \multirow{2}{*}{} & \multicolumn{2}{|c|}{ Age at $\mathbf{1}^{\text {st }}$ Visit for Functional Abdominal Pain } & \multicolumn{2}{|c|}{ Age At Time Of Inclusion Into Study } \\
\cline { 2 - 5 } & $\mathbf{n}$ & $\mathbf{\%}$ & $\mathbf{n}$ \\
\hline \hline$<1$ years & 8 & $14 \%$ & -- & - \\
\hline $1-3$ years & 14 & $25 \%$ & -- & - \\
\hline $4-7$ years & 19 & $33 \%$ & 226 & $52 \%$ \\
\hline $8-11$ years & 10 & $18 \%$ & 115 & $26 \%$ \\
\hline$>12$ years & 6 & $11 \%$ & 94 & $22 \%$ \\
\hline
\end{tabular}

abdominal pain in population and school-based samples, and depended on the age of the children and the definition used [18].

We found that in $95.9 \%$ the abdominal pain was due to a functional gastrointestinal disorder, most often due to functional constipation. Only in $14 \%$ of children with chronic abdominal pain was the functional abdominal pain not related to functional constipation; it was due to childhood functional abdominal pain in $9 \%$ and due to colic in 5\%. Uc et al. [19], using a questionnaire in 243 African-American school-age children who came for an annual school physical to a community clinic in Little Rock, Arkansas, USA, found that $19.3 \%$ fit the Rome II criteria for functional gastrointestinal disorders [2]; $0.8 \%$ had symptoms of functional dyspepsia, none had irritable bowel syndrome, $0.4 \%$ had functional abdominal pain syndrome, $0.4 \%$ had abdominal migraine, $2.5 \%$ had aerophagia, and $16 \%$ had constipation with $26 \%$ of the constipated children complaining of functional abdominal pain (personal communication).

We found that functional constipation was the most frequent cause of functional abdominal pain in children. It was responsible for $83 \%$ of all chronic abdominal pain, and for $86 \%$ of all functional abdominal pain. Our experience shows there is no substitute for direct questioning related to details of defecation and a thorough examination, including a rectal examination in the evaluation of a child with chronic abdominal pain. A plain abdominal X-ray may be necessary in those who had a recent bowel movement and no stool mass in the rectal ampulla and in those who are very obese. That constipation is the cause of chronic abdominal pain and not just associated with abdominal pain is supported by our outcome data which showed relief of abdominal pain with adequate laxative treatment. Our center has been using the Iowa definition for constipation since early 1980 . These classical Iowa criteria were more recently agreed upon by the PACCT group [20] and adopted by the Rome III committee for child/adolescents [4]. The authors and others had previously reported that many children, approximately $50 \%$, with longstanding functional constipation with or without faecal incontinence evaluated in tertiary care clinics suffered from abdominal pain $[13,21-23]$. A higher percentage $(72 \%)$ of our children seen for functional constipation in a primary care setting complained of functional abdominal pain. Constipation as a major cause of chronic abdominal pain in children, from toddler age to the preteen years, has been previously reported [24-26]. The study by Eidlitz-Markus et al. [24] supports our findings that functional constipation is a frequent cause of functional abdominal pain. In this prospec- tive study, 76 children were examined in a tertiary care center for recurrent attacks of abdominal pain and $57.4 \%$ had functional constipation. Constipation obvious by history was present in $14.7 \%$, but $42.6 \%$ had occult constipation, defined as absence of constipation complaints in the initial history or of symptoms to indicate the presence of constipation. The diagnosis was made by rectal examination and/or plain abdominal X-ray. In $83 \%$ of these children, the abdominal pain had subsided or disappeared within 2 weeks to 3 months of treatment for constipation, and in $96.5 \%$ at the $1-1.5$ year follow-up [24].

In taking the history and examining the child, the clinicians first task is to rule out the wide range of organic disorders that may present with chronic abdominal pain. The prevalence rates of organic disease ranged from $5 \%$ in the general population to $40 \%$ in a paediatric gastroenterology practice [27]. The prevalence for chronic abdominal pain due to underlying organic disease in our children was only $3 \%$. Kokkonen et al. [28] reported a much higher rate of organic disease in Finish 10- to 11-year old children, including milk protein intolerance, lactose intolerance, celiac disease and Helicobacter pylori infection.

Limitations of our study: Medications for functional abdominal pain are often prescribed judiciously as an individual approach to relieve symptoms and disability. Treatment suggestions for functional abdominal pain have included acid-reduction therapy, low doses of psychotropic agents, and osmotic laxatives even though none have been evaluated in a double-blind randomized trial. Diagnoses such as gastroesophageal reflux disease and even constipation may have been given to allow for a treatment trial with acidsuppressive therapy or laxative. We therefore reviewed the treatment outcome and long-term outcome in these children to verify that the diagnosis was correct, but have to consider a placebo effect in some of the children. If constipationpredominant irritable bowel syndrome was a cause of abdominal pain, could not be determined because of the similarity of symptoms in constipation-predominant irritable bowel syndrome and in functional constipation [29]. Constipation-predominant irritable bowel syndrome is a symptombased diagnosis, requiring chronic abdominal pain and symptoms of constipation for diagnosis, symptoms which are also present in many children with functional constipation [30]. Others believe that functional constipation may co-exist with constipation-predominant irritable bowel syndrome [31].

Although a prospective design could have provided a better opportunity for standardized data collection at the time 
of the encounter, we feel our design is methodologically sound. In view of the paucity of published literature showing a high frequency of constipation as a cause of chronic abdominal pain, we thought it important to publish our experience from our primary academic care clinic. We found that functional constipation was the cause of chronic abdominal pain in $83 \%$ of cases.

\section{CONCLUSIONS}

We found that functional constipation was the most frequent cause of chronic abdominal pain in children and should be considered first in a child complaining of recurrent or chronic abdominal pain presenting to a primary care physician.

\section{ACKNOWLEDGEMENTS}

The authors thank Meenakshi Verma, MBBS and Ravi Prasad Avati Nanjundappa, MBBS for help with the chart reviews.

\section{REFERENCES}

[1] Berger MY, Gieteling MJ, Benninga MA. Chronic abdominal pain in children. BMJ 2007; 334(7601): 997-1002.

[2] Rasquin-Weber A, Hyman PE, Cucchiara S, et al. Childhood functional gastrointestinal disorders. Gut 1999; 45: SII60-8.

[3] Apley J, Naish N. Recurrent abdominal pains: a field survey of 1000 school children. Arch Dis Child 1958; 33(168): 165-70.

[4] Rasquin A, Di Lorenzo C, Forbes D, et al. Childhood functional gastrointestinal disorders: child/adolescent. Gastroenterology 2006; 130(5): 1527-37.

[5] Boey C, Yap S, Goh KL. The prevalence of recurrent abdominal pain in 11- to 16-year-old Malaysian schoolchildren. J Paediatr Child Health 2000; 36(2): 114-6.

[6] Di Lorenzo C, Colletti RB, Lehmann HP, et al. Chronic abdominal pain in children: a technical report of the American Academy of Pediatrics and the North American Society for Pediatric Gastroenterology, Hepatology and Nutrition. J Pediatr Gastroenterol Nutr 2005; 40(3): 249-61.

[7] Di Lorenzo C, Colletti RB, Lehmann HP, et al. Chronic abdominal pain in children: a clinical report of the American Academy of Pediatrics and the North American Society for Pediatric Gastroenterology, Hepatology and Nutrition. J Pediatr Gastroenterol Nutr 2005; 40(3): 245-8 and Pediatrics 2005; 115(3): 812-5.

[8] Current Procedural Terminology $\left(\mathrm{CPT}^{\circledR}\right)$ 2005. American Medical Association. AMA press, 2004

[9] Loening-Baucke V. Factors determining outcome in children with chronic constipation and faecal soiling. Gut 1989; 30(7); 999-1006.

[10] Voskuijl WP, Heijmans J, Heijmans A, Taminiau JAJM, Benninga MA. Use of Rome II criteria in childhood defecation disorders: applicability in clinical and research practice. J Pediatr 2004; 145(2): 213-7.

[11] Loening-Baucke V. Modulation of abnormal defecation dynamics by biofeedback treatment in chronically constipated children with encopresis. J Pediatr 1990; 116(2): 214-22.
[12] Benninga MA, Büller HA, Heymans HS, Tytgat GN, Taminiau JA. Is encopresis always the result of constipation? Arch Dis Child 1994; 71(3): 186-93.

[13] Loening-Baucke V. Functional fecal retention with encopresis in childhood. J Pediatr Gastroenterol Nutr 2004; 38(1): 79-84.

[14] Hyman PE, Milla PJ, Benninga MA, et al. Childhood gastrointestinal disorders: neonate/toddler. Gastroenterology 2006; 130(5): 1519-26.

[15] Ramchandani PG, Hotopf M, Sandhu B, Stein A, and the ALSPAC study team. The epidemiology of recurrent abdominal pain from 2 to 6 years of age: results of a large, population-base study. Pediatrics 2005 ; 116(1): 46-50.

[16] Ludvigsson JF, Abis Study Group. Epidemiological study of constipation and other gastrointestinal symptoms in 8000 children. Acta Paediatr 2006; 95(5): 573-80.

[17] Hyams JS, Burke G, Davis PM, Rzepski B, Andrulonis PA. Abdominal pain and irritable bowel syndrome in adolescents: a community-based study. J Pediatr 1996; 129(2): 220-6.

[18] Chitkara DK, Rawat DJ, Talley NJ. The epidemiology of childhood recurrent abdominal pain in western countries: a systemic review. Am J Gastroenterol 2005; 100(8): 1868-75.

[19] Uc A, Hyman PE, Walker LS. Functional gastrointestinal disorders in African American children in primary care. J Pediatr Gastroenterol Nutr 2006; 42(3): 270-4.

[20] Benninga MA, Candy DCA, Catto-Smith AG, et al. The Paris consensus on childhood constipation terminology (PACCT) group. J Pediatr Gastroenterol Nutr 2005; 40(3): 273-5.

[21] Keuzenkamp-Jansen CW, Fijnvandraat CJ, Kneepkens CMF, Douwes AC. Diagnostic dilemmas and results of treatment for chronic constipation. Arch Dis Child 1996; 75(1): 36-41.

[22] Loening-Baucke V, Miele E, Staiano A. Fiber (glucomannan) is beneficial in the treatment of childhood constipation. Pediatrics 2004; 113(3 Pt 1): e259-64.

[23] Chitkara DK, Talley NJ, Weaver AM, et al. 3rd Incidence of presentation of common functional gastrointestinal disorders in children from birth to 5 years: a cohort study. Clin Gastroenterol Hep 2007; 5(2): 186-91.

[24] Eidlitz-Markus T, Mimouni M, Zeharia A, Nussinovitch M, Amir J. Occult constipation: a common cause of recurrent abdominal pain in childhood. Israel Med Assoc J 2004; 6(11): 677-80.

[25] Lake AM. Chronic abdominal pain in childhood: diagnosis and management. Am Fam Phys 1999; 59(7): 1823-30. Available at: www.aafp.orgafp/990401ap/1823.html. (Assessed January 22, 2008)

[26] Thiessen PN. Recurrent abdominal pain. Pediatr Rev 2002; 23(2): 39-45.

[27] Stordal K, Nygaard EA, Bentsen B. Organic abnormalities in recurrent abdominal pain in children. Acta Paediatr 2001; 90(6): 638-42.

[28] Kokkonen J, Haapalathi M, Tikkanen S, Karttunen R, Savilahti E. Gastrointestinal complaints and diagnosis in children: a populationbased study. Acta Paediatr 2004; 93(7): 880-6.

[29] Talley NJ. Differentiating functional constipation from constipation-predominant irritable bowel syndrome: management implications. Rev Gastroenterol Disord 2005; 5(1): 1-9.

[30] Longstreth GF. Definition and classification of irritable bowel syndrome: current consensus and controversies. Gastroenterol Clin N Am 2005; 34(2): 173-87.

[31] Plunkett A, Phillips CP, Beattie RM. Management of chronic functional constipation in childhood. Pediatr Drugs 2007; 9(1): 33-46. 